\title{
A!
}

This is an electronic reprint of the original article.

This reprint may differ from the original in pagination and typographic detail.

Tois, J.; Franzen, R.; Koskinen, A.M.P.

\section{Synthetic Approaches towards Indoles on Solid phase - Recent Advances and Future Directions}

\section{Published in:}

Tetrahedron

DOI:

$10.1016 / \mathrm{S} 0040-4020(03) 00851-2$

Published: 01/01/2003

Document Version

Peer reviewed version

Please cite the original version:

Tois, J., Franzen, R., \& Koskinen, A. M. P. (2003). Synthetic Approaches towards Indoles on Solid phase Recent Advances and Future Directions. Tetrahedron, 59, 5395-5405. https://doi.org/10.1016/S00404020(03)00851-2

This material is protected by copyright and other intellectual property rights, and duplication or sale of all or part of any of the repository collections is not permitted, except that material may be duplicated by you for your research use or educational purposes in electronic or print form. You must obtain permission for any other use. Electronic or print copies may not be offered, whether for sale or otherwise to anyone who is not an authorised user. 


\title{
Synthetic approaches towards indoles on solid phase recent advances and future directions
}

\author{
Jan Tois, ${ }^{\mathrm{a}, *}$ Robert Franzén ${ }^{\mathrm{b}}$ and Ari Koskinen ${ }^{\mathrm{a}}$ \\ ${ }^{a}$ Laboratory of Organic Chemistry, Helsinki University of Technology, P.O. Box 6100, FIN-02015, Finland \\ ${ }^{\mathrm{b}}$ Tampere University of Technology, Institute of Materials Chemistry, P.O. Box 541, FIN-33101, Finland
}

\section{Contents}

1. Introduction

2. Preparation of the indole core on solid phase

2.1. Fischer cyclisation on solid phase

2.2. Palladium-catalysed cyclisation on solid phase

2.3. Madelung cyclisation and intramolecular Wittig reaction in synthesis of indoles

2.4. Solid-phase Nenitzescu indole synthesis

2.5. Other intramolecular cyclizations giving the indole or structurally closely-related core

3. Modification of substituents on the indole ring

3.1. Palladium-catalysed modifications of the indole ring on solid phase

3.2. Modifications leading to tertiary amines

3.3. Modification leading to amides

3.4. Direct functionalisation of the indole ring

3.5. Modification of indoles by substitution at nitrogen

3.6. Modification of the 2-position by Pictet-Spengler reaction

3.7. Indole 3-position modifications

3.8. Functionalisations to other positions

4. Conclusions

\section{Introduction}

Indoles or molecules containing the indole moiety have efficiently been synthesised for more than 100 years in solution. ${ }^{1}$ The first preparation of indole dates from 1866 and the Fischer indole synthesis was introduced as the most versatile method for preparing indoles in $1883 .^{2}$ Efficient preparation on solid phase, however, dates back only about 10 years. Although most of the published papers have focused on synthetic methods developed for the addition or

Abbreviations: TEA, triethylamine; DMA, dimethylacetamide; TFA, trifluoroacetic acid; TMG, 1,1,3,3-tetramethylguanidine; BINAP, 2,2'bis(diphenylphosphino)-1,1-binaphtyl; TMOF, trimethylortoformate; NMP, 1-methyl-2-pyrrolidinone; AIBN, azobis(isobutyronitrile); DCC, dicyclohexylcarbodiimide; DMAP, 4- $N, N$-dimethylpyridine; dppf, $1,1^{\prime}$ bis(diphenylphosphino)ferrocene; dba, dibenzylideneacetone; NBS, $\mathrm{N}$ bromosuccinimide; NIS, $N$-iodosuccinimide; DBU, 1,8diazobicyclo[5.4.0] undec-7-ene; HOBt, 1-hydroxybenzotriazole; DME, 1,2-dimethoxyethane; NMFA, $N$-methylformanilide; DCE, dichloroethane. modification of substituents on the indole ring, a few very efficient methods for the preparation of indoles from benzenoid precursors have been introduced on solid phase. Most of these methods are palladium-catalysed cyclisations, but a few examples describe the indole synthesis through other cyclisation methods such as the Fischer indole synthesis, Madelung synthesis, the intramolecular Wittig reaction or the solid-phase Nenitzescu indole synthesis. Furthermore, a few miscellaneous cyclisations leading to indoles or structurally related compounds have been performed on solid phase. The addition or modification of substituents on the indole ring, on the other hand, includes functional group transformations and direct functionalisations adopted to solid-phase organic synthesis. This part covers only circumstances where readily adorned indole cores have been attached to a solid support and the ring system has been modified. Occasions where indoles have been used as a part of the linker system ${ }^{3,4}$ are not included. This report summarises the literature published until July 2002 describing methods for either the preparation of the 
indole moiety or the modification of the indole core on a variety of polymer-supported resins. Further details of the experimental conditions are available from the primary literature references. All of the publications cited are from refereed journals and not from patents. A search in Chemical Abstracts, using the keyword 'indole' combined with other keywords such as 'solid-phase synthesis', 'combinatorial chemistry' and 'solid support', has been performed to ensure that most of the references on the subject have been covered.

\section{Preparation of the indole core on solid phase}

\subsection{Fischer cyclisation on solid phase}

The Fischer indole synthesis is still the most important preparative method for indoles in solution. During the Fischer indole cyclisation, arylhydrazones of aldehydes or ketones are converted to indoles by a process which involves $o$-substitution via a sigmatropic rearrangement. In this process, ammonia is generated through the formation of an imine of an $o$-aminobenzyl ketone which cyclises and aromatises. The Borsche synthesis of tetrahydrocarbazoles is a special case of the Fischer indole synthesis in which cyclohexanone phenylhydrazones are used as the starting material. Cyclisation of $\boldsymbol{\alpha}$-halogeno-ketones give indoles when reacted with anilines or aromatic amines (Bischler indole synthesis). On solid supports, the Fischer indole synthesis was first adapted to the solid phase by Hutchins and Chapman. ${ }^{5}$ The synthetic route involved the use of support-bound 4-benzoylbutyric acid $\mathbf{1}$ and a variety of substituted phenylhydrazine hydrochlorides as the starting materials. Since the indole cyclisation required acid catalysis, the hydroxymethylbenzoic acid (HMB) linker was chosen for the preparation of 2-arylindoles 2 (Scheme 1). Although the purity of the cleaved indoles was high, the overall yields remained moderate. This

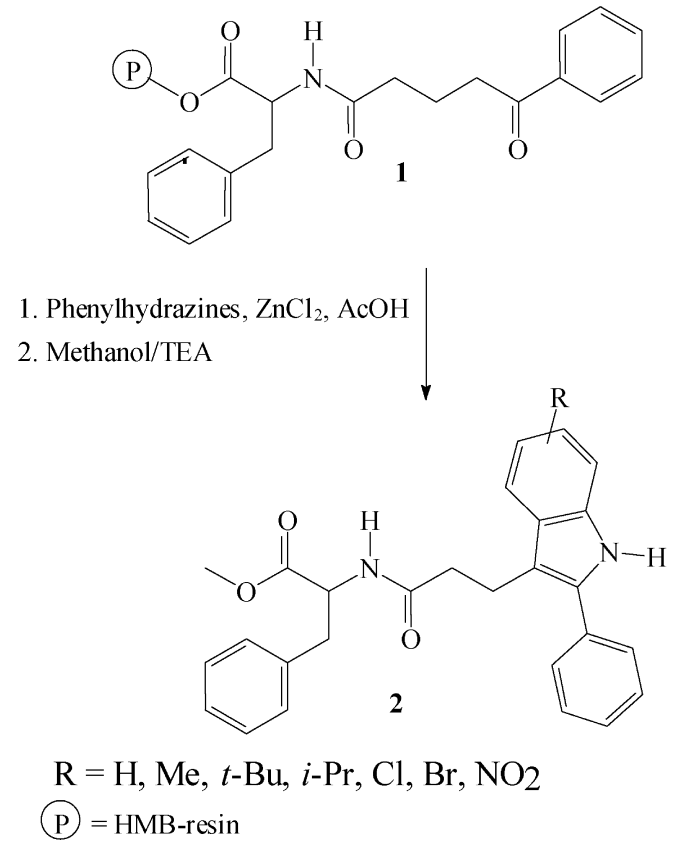

Scheme 1. research group has also adopted this method to dendrimer supports. ${ }^{6}$ Later, Cheng and Chapman ${ }^{7}$ described a method for the solid-phase synthesis of spiro indolines using the Fischer indole reaction. Several products could be isolated in good yields and high purity. Various arylhydrazines reacted with a polymer-supported piperidine-4-carboxaldehyde in TFA/DCM. In conclusion, only a few methods have been developed for the utilisation of the Fischer indole synthesis on solid phase. It is therefore anticipated that the method will be further developed and more efficiently transferred to the polymer matrix within the next few years, making it more suitable for combinatorial chemistry purposes. The possibilities of combining Fischer synthesis and palladium chemistry will be discussed in next section.

\subsection{Palladium-catalysed cyclisation on solid phase}

Methods for aromatic substitution based on catalysis by transition metals, mainly palladium, have proven to be efficient approaches towards indoles on solid phase. In the intramolecular Heck reaction, an $o$-halo- $N$-allylaniline is efficiently cyclised to yield the indole in good yield and high purity. This versatile method has been reported in several papers. Yun and Mohan ${ }^{8}$ described the intramolecular Heck reaction of polymer-bound aryl halides $(\mathbf{3} \rightarrow \mathbf{6})$ and a similar approach was later published by Balasubramanian et al. ${ }^{9}$ for 2-oxindoles. Instead of coupling the aryl moiety to the solid support, Zhang et al. ${ }^{10}$ immobilised the $\gamma$-bromocrotonic acid, thus obtaining the amide 7 (Scheme 2). In all these papers, the efficiency of the cyclisation was demonstrated by the use of different starting materials. The palladiummediated intramolecular heteroannulation has also proved to be a valuable method for the synthesis of the indole moiety on solid phase. New carbon-carbon bonds are
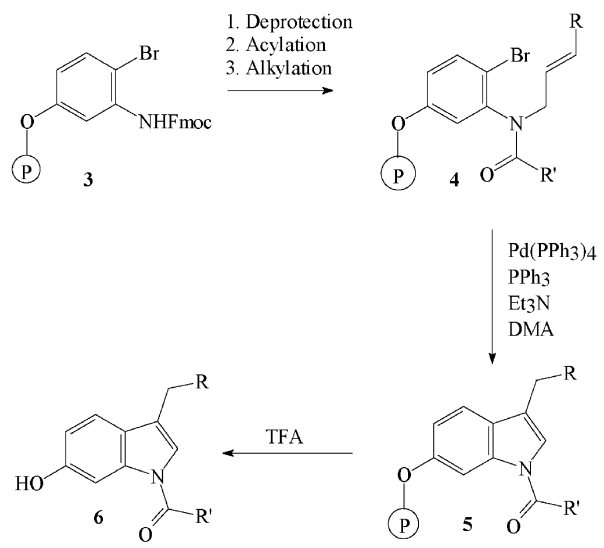

$\mathrm{R}=\mathrm{H}, \mathrm{Ph}, \mathrm{Me} ; \mathrm{R}^{\prime}=\mathrm{Et}, i-\mathrm{Pr}, \mathrm{Ph}, 3-\mathrm{OMe}-\mathrm{Ph}$

(P) $=$ TentaGel S-NH 2 -resin

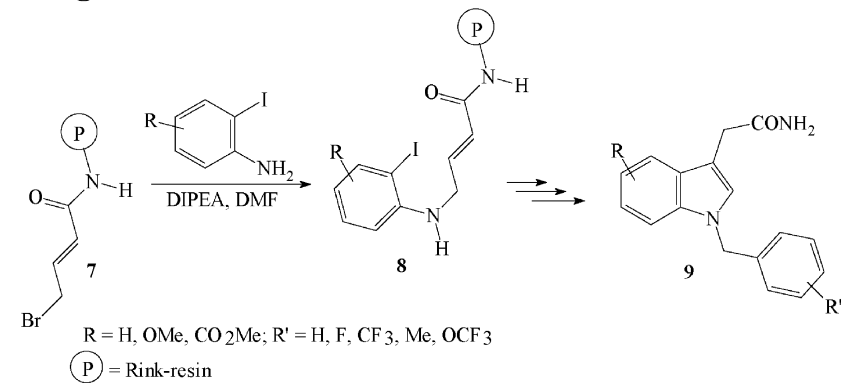

Scheme 2. 
created through a palladium-catalysed addition of acetylenes to $o$-iodoanilines. Recent examples include the work by Bedeschi et al. ${ }^{11}$ where 2 -substituted indoles could be obtained in the reaction between resin-attached $o$-iodoaniline $\mathbf{1 0}$ and a terminal alkyne $(\mathbf{1 0} \longrightarrow \mathbf{1 1})$. Zhang et al. ${ }^{12}$ and Smith et al. ${ }^{13}$ developed this methodology for internal alkynes and Collini and Ellingboe ${ }^{14}$ reported a solid-phase synthesis of indoles with three independently variable components. Zhang et al. ${ }^{15}$ and Schultz et al. ${ }^{16}$ have demonstrated that a palladium-mediated heteroannulation of terminal alkynes can be performed using a traceless sulfonamide linker. The discovery makes it possible to produce indoles with either a free hydrogen-bond donor or a hydrophobic group at $N-1(\mathbf{1 2} \longrightarrow \mathbf{1 3})($ Scheme 3$)$.

Recently, a palladium-catalysed cyclisation of a $\beta-(2-$ halophenyl)amino-substituted $\alpha, \beta$-unsaturated ester 16 was found to be effective for the solid-phase synthesis of indole 3-carboxylates ${ }^{17}$ 17. The polymer-bound enamino ester was synthesised by acid-catalysed condensation or by palladium(II) chloride-catalysed oxidative amination reaction $(\mathbf{1 4} \rightarrow \mathbf{1 7})$ (Scheme 4).

While these methods are of great importance, a drawback is the requirement of a bifunctional precursor for the formation of a new $\mathrm{C}-\mathrm{C}$ and $\mathrm{C}-\mathrm{N}$ bonds. This means that, in order to prepare an indole with one substituent on the aromatic ring, one must employ an aromatic precursor with three substituents. There are only a limited number of commercially available highly-functionalised aromatic compounds and time-consuming extra work is often needed to prepare the benzenoid starting materials. Buchwald et al. ${ }^{18,19}$ have demonstrated in solution an efficient palladium-catalysed strategy for the preparation of indoles. This straightforward two-step synthesis where a palladium-catalysed reaction is followed by Fischer indolisation could be the next cyclisation reaction on solid phase $(\mathbf{1 8} \rightarrow \mathbf{2 0})$ (Scheme 5$)$.
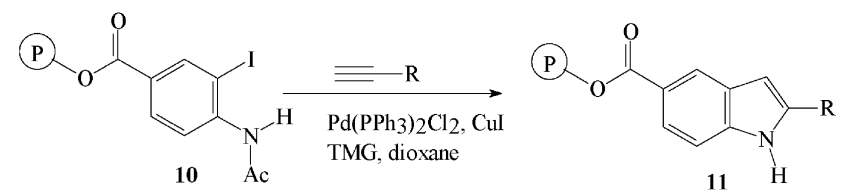

$\mathrm{R}=$ Alkyl, Ph
P $=$ TentaGel-OH-resin
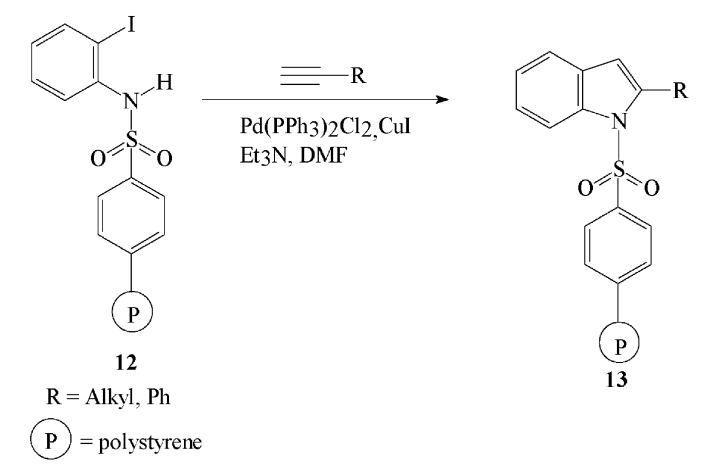

Scheme 3.

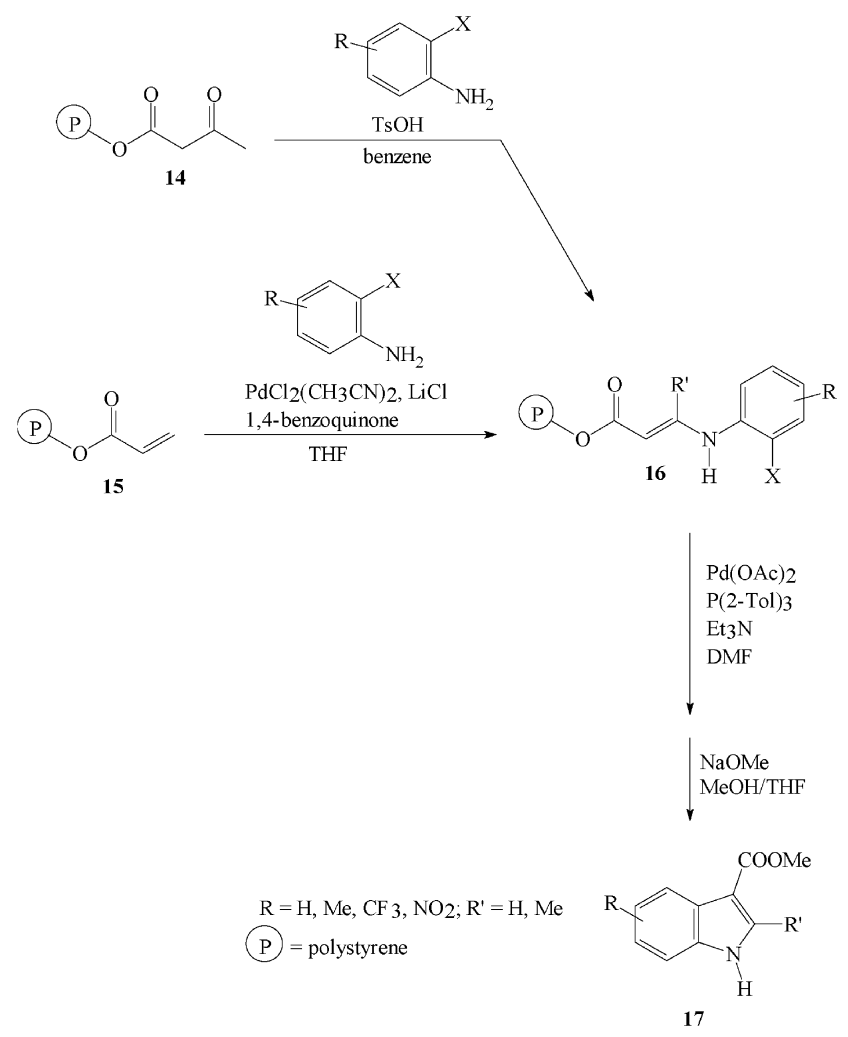

Scheme 4.

\subsection{Madelung cyclisation and intramolecular Wittig reaction in synthesis of indoles}

Wacker and Kasireddy ${ }^{20}$ have utilised the modified Madelung indole synthesis successfully on solid phase. 2,3-Disubstituted indoles were obtained in excellent yields and purities. Bal-resin $\mathbf{2 1}$ was functionalised by reductive amination followed by acylation, cyclisation and acidpromoted cleavage $(\mathbf{2 1 \rightarrow 2 5})$ (Scheme 6).

A variation of the Madelung cyclisation involves installing a functional group in the benzenoid precursor which can facilitate the cyclisation. Such a group is, for example, a triphenylphosphonium substituent that converts the reaction

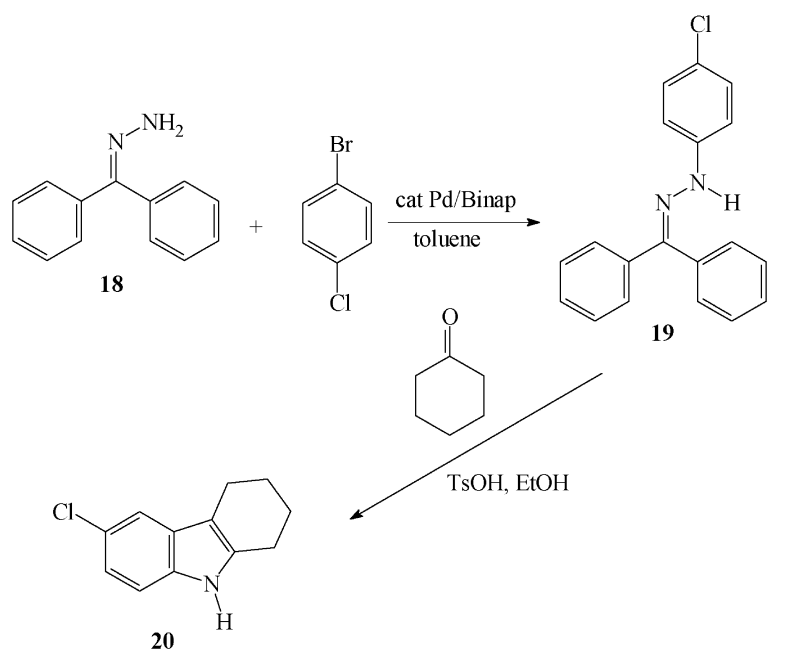

Scheme 5. 


$$
\overbrace{21}^{\mathrm{CHO}}+\overbrace{\mathrm{DCM}}^{\mathrm{CN}} \underset{\mathrm{TMOF}, \mathrm{NaBH}(\mathrm{OAc})_{3}}{\stackrel{\mathrm{NH}_{2}}{\longrightarrow}}
$$
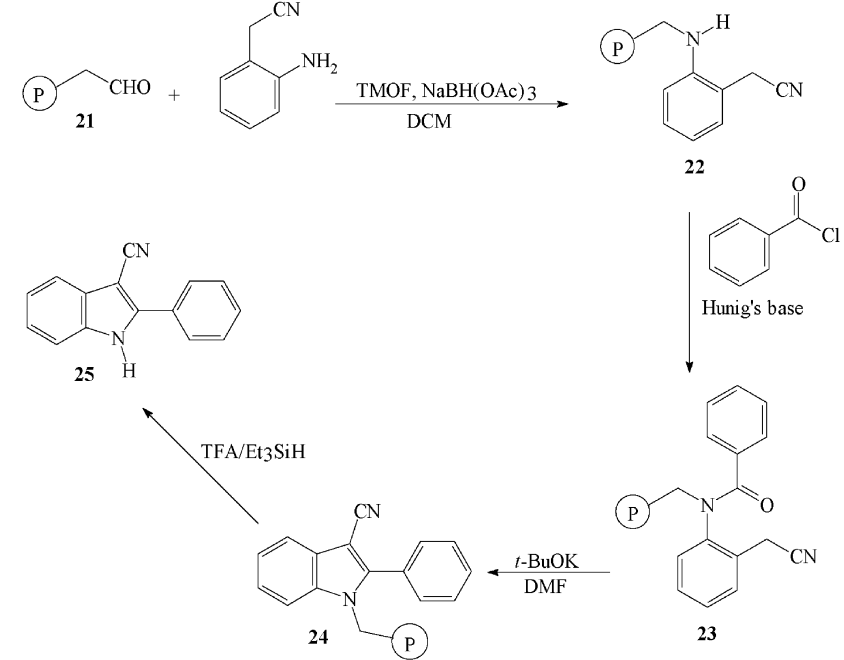

P $=$ Bal-resin

Scheme 6 .

into an intramolecular Wittig condensation. The required phosphonium salts $\mathbf{2 8}$ can be prepared from an $o$ nitrobenzyl chloride or bromide. Hughes ${ }^{21}$ utilised the phosphonium group as a traceless linker for the synthesis of indole 29 on solid phase in $78 \%$ yield. An advantage is that the phosphine oxide byproduct remains bound to the polymer and could be separated simply by filtration $(\mathbf{2 6} \rightarrow \mathbf{2 8})$ (Scheme 7).

\subsection{Solid-phase Nenitzescu indole synthesis}

In this classic organic reaction, 5-hydroxyindole derivatives can be synthesised by condensation of $p$-benzoquinone with $\beta$-aminocrotonic esters. Since many important natural products and molecules possess the 5-hydroxyindole skeleton, the recent discovery of the solid-phase version

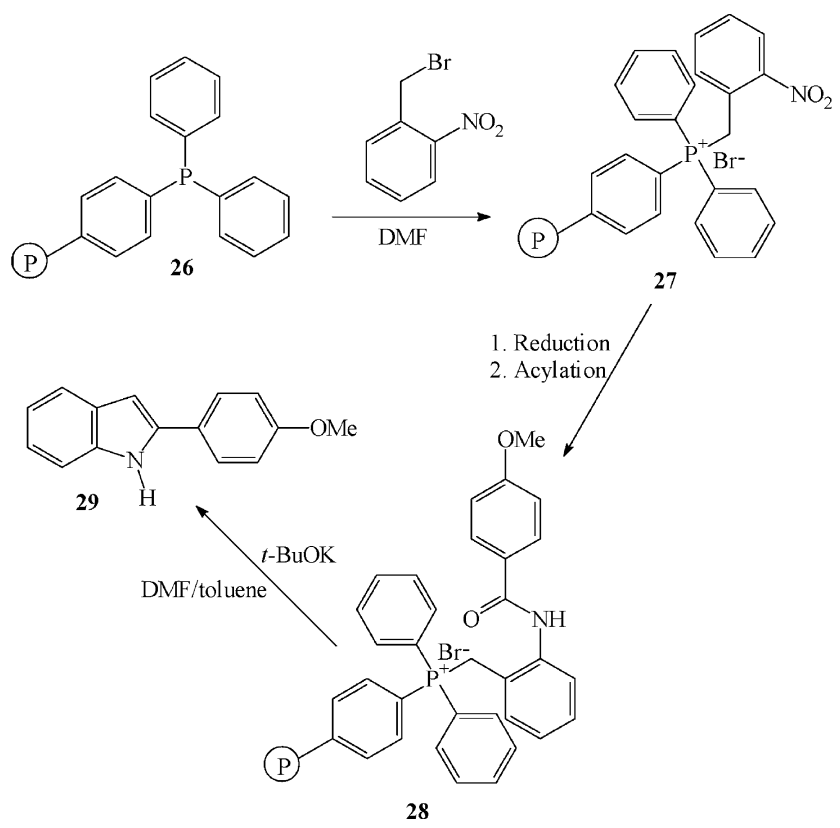

Scheme 7.
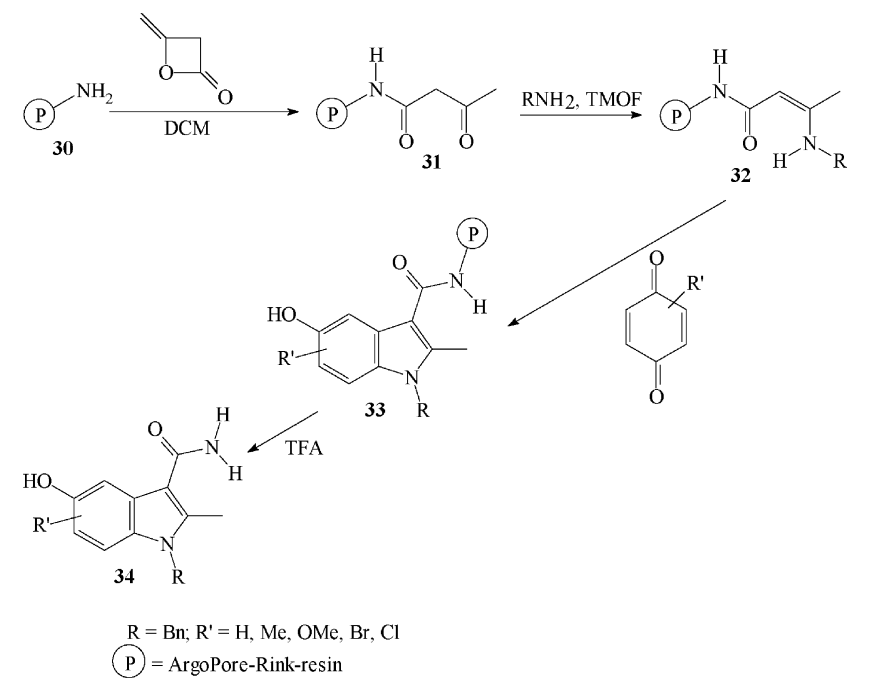

Scheme 8 .

by Ketcha et al. ${ }^{22}$ gave a new tool to be used in the combinatorial preparation of 5-hydroxyindole-3-carboxamides 34. The solid-phase process involved sequential acetoacylation, condensation with primary amines, addition of 1 ,4-benzoquinones and cleavage by TFA $(\mathbf{3 0} \rightarrow \mathbf{3 4})$ (Scheme 8).

\subsection{Other intramolecular cyclizations giving the indole or structurally closely-related core}

Other methods for the preparation of indoles and indole analogues include the preparation of 1-hydroxy-6-indolecarboxylic acids 37. ${ }^{23}$ The compounds were obtained by treatment of Wang resin-bound 4-fluoro-3-nitrobenzoic acid 35 with 1,3-dicarbonyl compounds, followed by reduction and cleavage. Reductive cleavage of the $\mathrm{N}-\mathrm{O}$ bond was attempted, but was not successful (Scheme 9).

Nicolaou et al. ${ }^{24}$ have described a highly efficient method for the solid-phase synthesis of substituted indoline scaffolds. Substituted $o$-allylanilines were cycloadded onto a selenenyl bromide resin 39. Resin-bound indoline scaffold $\mathbf{4 0}$ was further elaborated and cleaved tracelessly $(\mathbf{3 9} \rightarrow \mathbf{4 1})$ (Scheme 10).

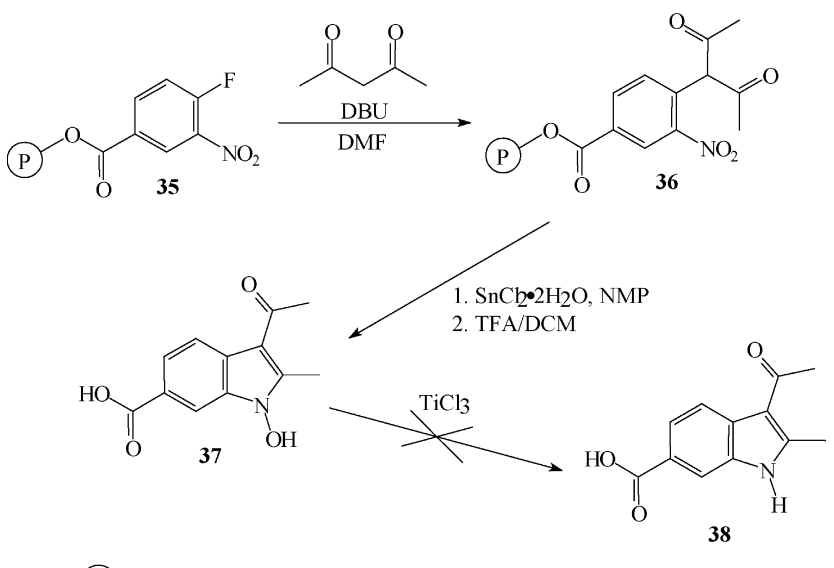

Scheme 9. 


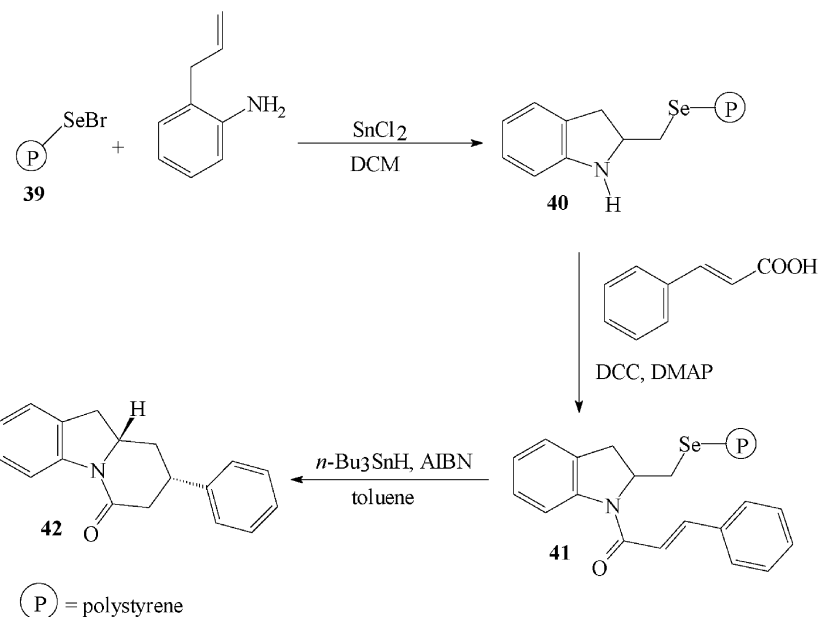

Scheme 10.

Recently, Hartley utilised titanium(IV) benzylidene reagents that allow traceless solid-phase synthesis of indoles. ${ }^{25}$ Resin-bound esters $\mathbf{4 3}$ were reacted with titanium benzylidene having a masked nucleophile in the $o$-position. The acid-stable ester is thus converted to an acid-labile enol ether 44. Deprotection of the nucleophile leads to the formation of an oxonium ion $\mathbf{4 6}$ and release of the indole from the resin 47. Although this traceless method provides indoles with high purity, a drawback is again the requirement of a bifunctional precursor for the formation of a new $\mathrm{C}-\mathrm{C}$ and $\mathrm{C}-\mathrm{N}$ bonds (Scheme 11).

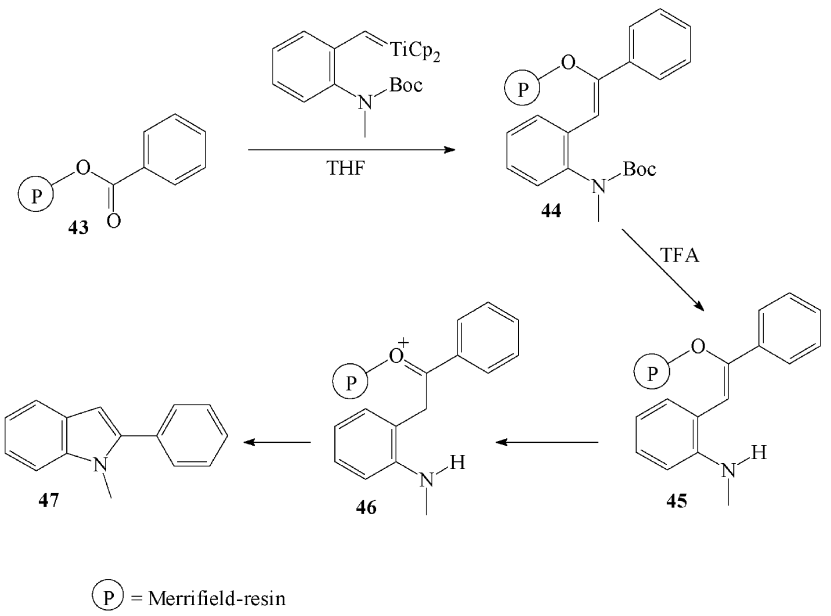

Scheme 11.

\section{Modification of substituents on the indole ring}

This part of the report covers circumstances where indole moieties are already adorned with suitable substituents before attachment to the solid support.

\subsection{Palladium-catalysed modifications of the indole ring on solid phase}

As in the case of cyclisations, also in the case of the ring modifications palladium plays an important role. Organo- boronic acids, stannanes, halides and palladium reagents are commercially available and the coupling reactions are one of the most studied reactions on solid phase. The indole structure has also been modified by these reactions. Smith et al. ${ }^{26}$ successfully utilised Suzuki and Stille couplings in their discovery of a novel, high-affinity h5- $\mathrm{HT}_{2 \mathrm{~A}}$ antagonist. In this small series of 2-aryltryptamines 49, the starting indole 48 was tethered to a Wang-carbamate linker. Traceless polystyrene sulfonyl chloride ( $\mathrm{PS}-\mathrm{TsCl}$ ) linkage was used by Schultz et al. ${ }^{16}$ when they modified the indole C-5 position by Sonagashira and Suzuki couplings. Both above methods are based on the couplings where the electrophilic component (halide) is attached to a solid support. The only example where the nucleophilic species 53 (stannane) is polymer bound has been reported by Gmeiner et al. ${ }^{27}$ Their linking strategy was also traceless and based on transacetalisation of diethoxymethyl (DEM)protected indoles (Scheme 12).

Zhang et al. ${ }^{12}$ introduced a halo substituent to the indole core by conversion of a trimethylsilyl group to bromo or iodo groups and they also mentioned organometallic coupling reactions. However, no descriptions of these reactions were mentioned (Scheme 13).
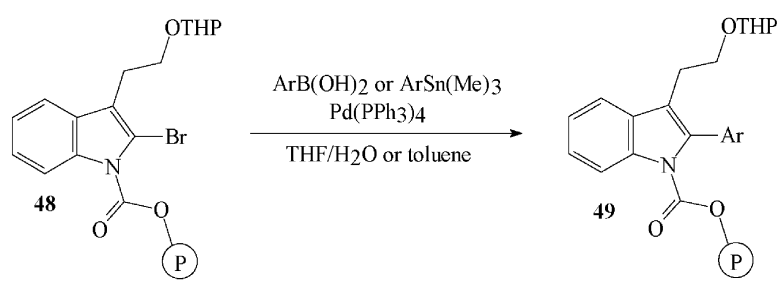

$$
\text { (P) = Wang-resin }
$$<smiles>[R]c1cc2cc(Br)ccc2n1S(=O)(=O)c1ccc(Br)cc1</smiles>
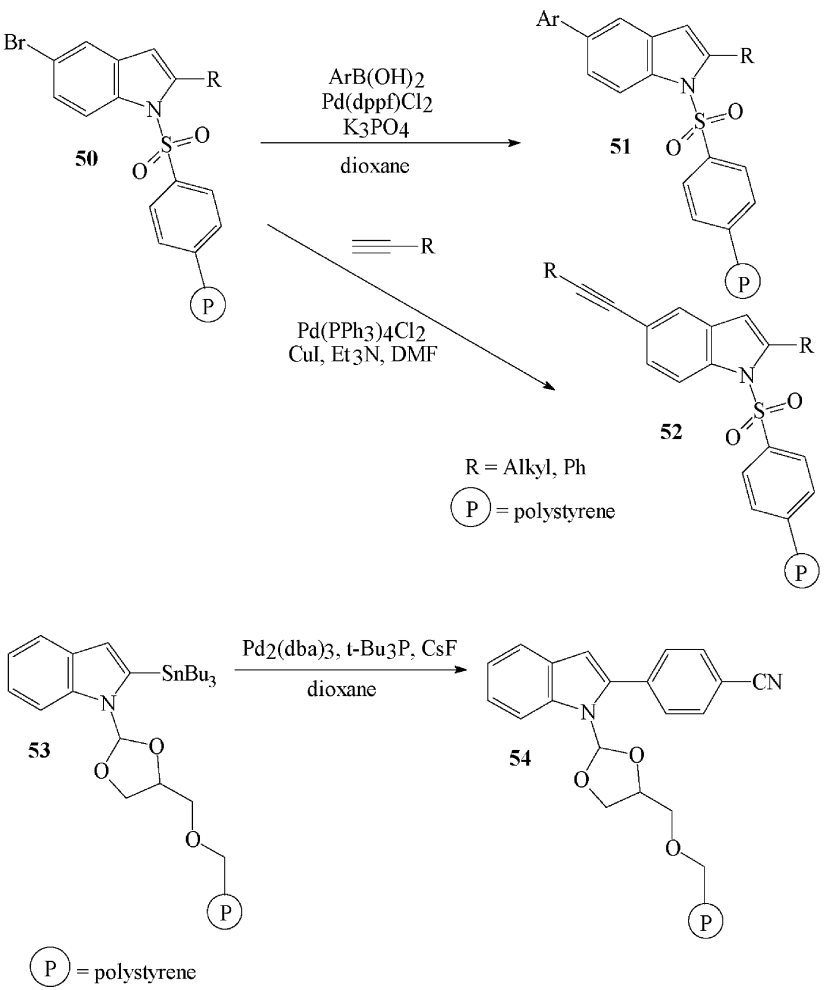

Scheme 12. 


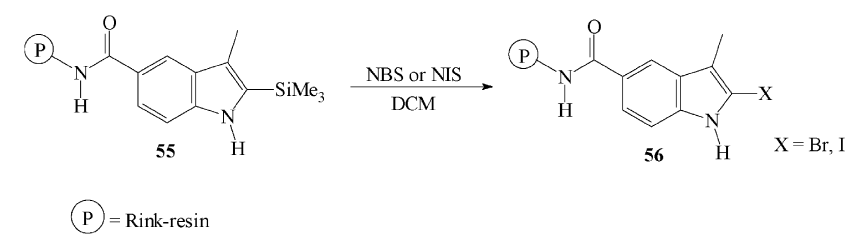

Scheme 13.

\subsection{Modifications leading to tertiary amines}

Gmeiner et al. ${ }^{28}$ modified the indole 2-position by treating the polymer-bound 2-chloromethylindoles 57 with arylpiperazines (Scheme 14). The compounds obtained were found as highly selective dopamine $\mathrm{D}_{4}$ receptor partial agonists. Smith et al. reported the use of polymer-bound triflates $\mathbf{5 9}$ in the preparation of tertiary amines. ${ }^{26}$

Tois and Franzén reported the preparation of 5-substituted 2-carboxyindoles 64 on solid support. ${ }^{29}$ Indole precursor 61 was tethered to Wang-resin via an ester bond followed by nitro group reduction. 5-Amino-2-carboxyindole derivatives could be more readily prepared on solid-phase than in solution. ${ }^{30}$ After reductive amination, alkylation and cleavage, 5-N,N-disubstituted 2-carboxyindoles were obtained. Only aromatic aldehydes and benzyl bromides were used in this study $(\mathbf{6 1} \rightarrow \mathbf{6 4})$ (Scheme 15).

Similarly Herget et al. ${ }^{31}$ utilised the reductive amination in the preparation of a teleocidin library. In this case, only aliphatic aldehydes were used $(\mathbf{6 5} \rightarrow \mathbf{6 6})$ (Scheme 15).

\subsection{Modification leading to amides}

Despite the fact that solid-phase peptide synthesis has appeared in the literature for four decades, only one example where an indole nucleus has been modified by amino acids exists. Zhang et al. ${ }^{10}$ modified the 5-position of the resin-bound carboxyindole 67. A minilibrary of 18

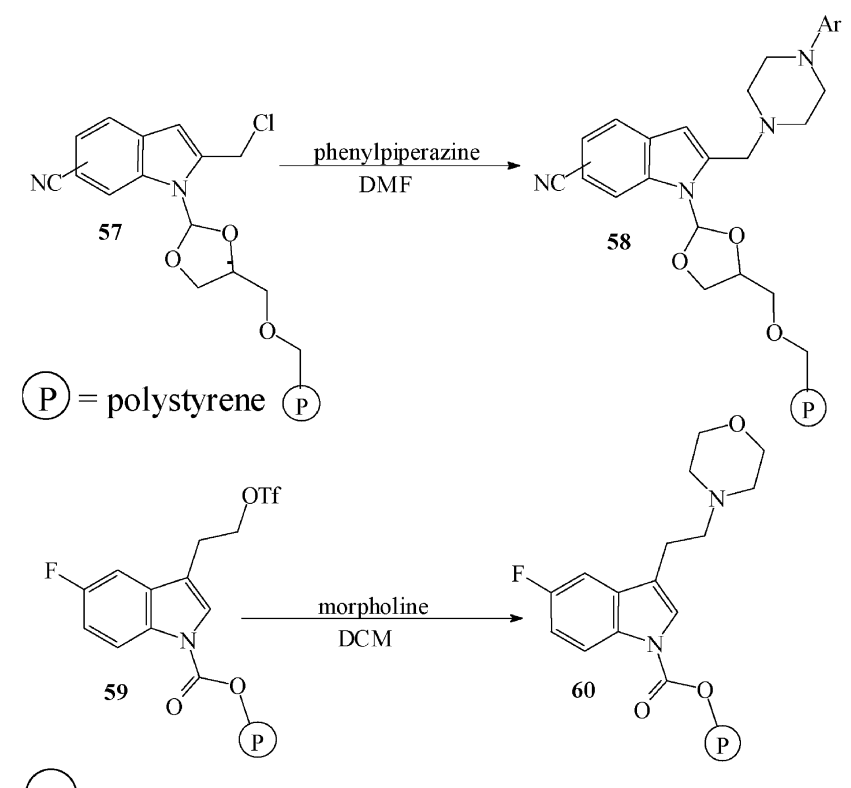

(P) = Wang-resin

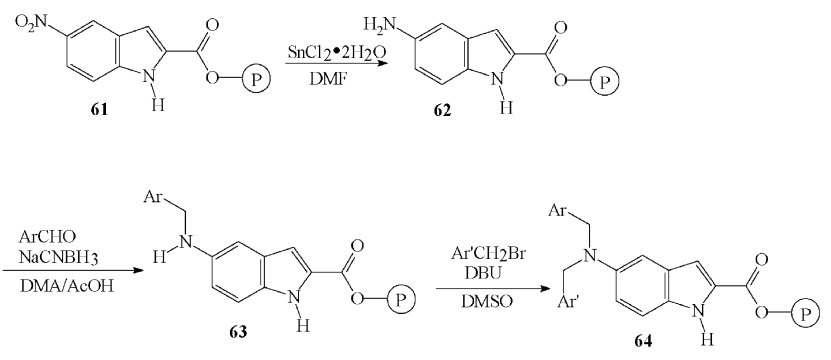

P $=$ Wang-resin

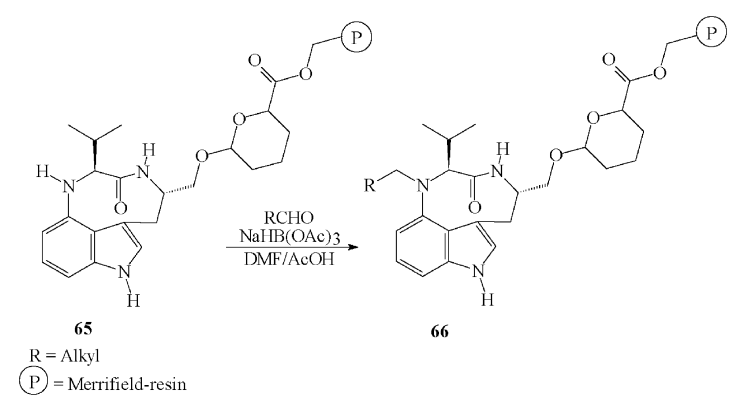

Scheme 15.

compounds was prepared and they utilised an uncommon methyl ester hydrolysis in their solid-supported library synthesis $(\mathbf{6 7} \rightarrow \mathbf{6 9})$ (Scheme 16).

\subsection{Direct functionalisation of the indole ring}

This section describes methods for direct ring substitution when the indole skeleton has already been attached to a polymer. Methods are introduced in numerical order of the substituents.

\subsection{Modification of indoles by substitution at nitrogen}

Procedures for $N-1$ substitution normally involve a basecatalysed nucleophilic substitution. The strong bases usually needed for deprotonation create some difficulties in solid-phase chemistry. Substituents should be tolerant under highly basic conditions and the linker system must be compatible. In fact, the only reported modifications on

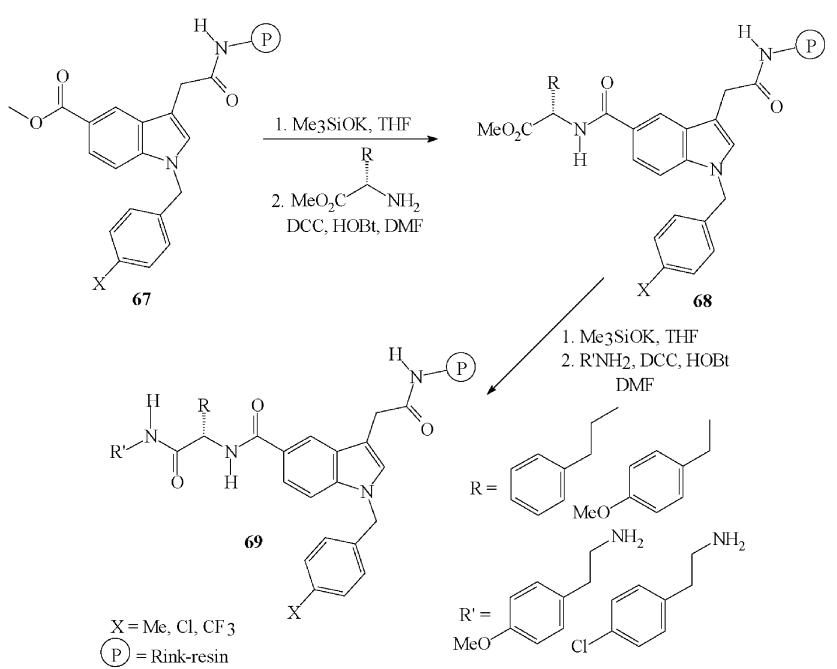

Scheme 16. 

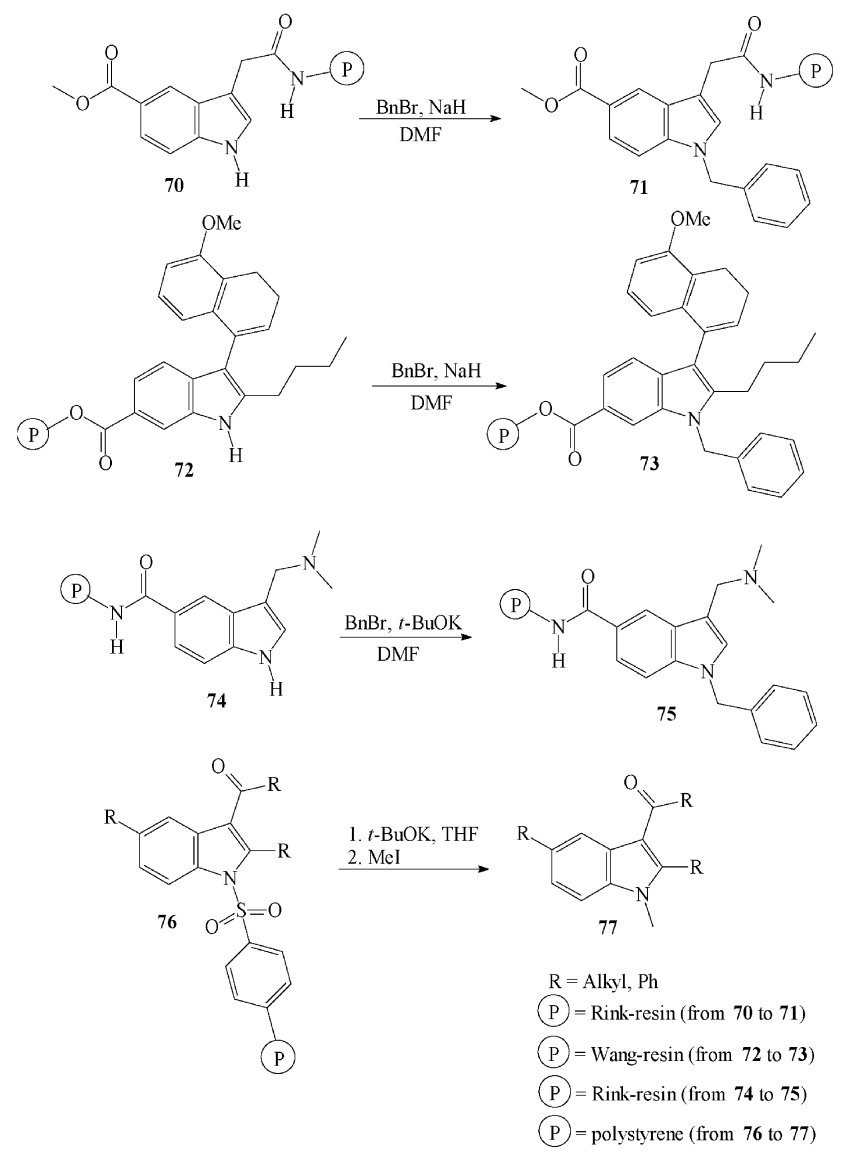

Scheme 17

solid-phase are alkylations. ${ }^{10,14,32}$ The deprotonation has been performed by $\mathrm{NaH}$ or $t$-BuOK and alkyl bromides have been used as electrophiles. One post-cleavage methylation has also been reported (Scheme 17). ${ }^{16}$

On the other hand, palladium ${ }^{33,34}$ or copper-catalysed ${ }^{35} \mathrm{~N}$ arylations reported in solution have not been reported on solid phase so far. Maybe, in the future, these reactions will be adapted to solid-phase chemistry and also alkylations or acylations with groups that have a directing effect toward C2 lithiation.

\subsection{Modification of the 2-position by Pictet-Spengler reaction}

The $\beta$-carboline skeleton is a key structural motif common to a large number of tryptophan-derived natural product alkaloids. Pictet-Spengler cyclisation gives access to this class of compounds and this reaction has been well studied in solid-phase chemistry. ${ }^{36-39}$ Both acid $^{36,37}$ and baselabile $^{38,39}$ linkers have been used to achieve the desired products. A variety of commercially available substituted aryl aldehydes, aliphatic aldehydes and ketones are viable substrates and thus allow the preparation of large $\beta$ carboline libraries $(\mathbf{7 8} \longrightarrow \mathbf{7 9}) \quad(\mathbf{8 0} \longrightarrow \mathbf{8 1}) \quad$ (Scheme 18). Recently, Grigg et al. ${ }^{40}$ represented a five-component solid-supported procedure were they utilised cycloaddition attachment, Pictet-Spengler reaction and, finally, $\operatorname{Pd}(0)$ catalysed reactions $(\mathbf{8 2} \rightarrow \mathbf{8 5})$ (Scheme 19).

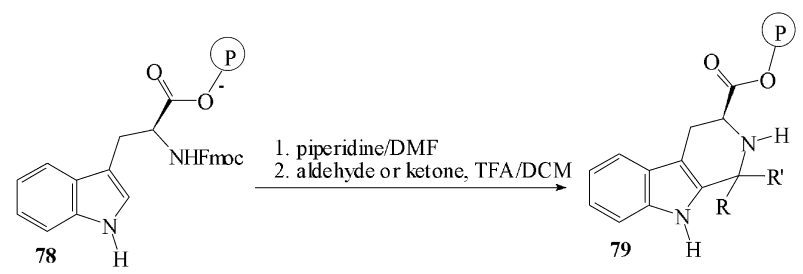

(P) = Wang-resin

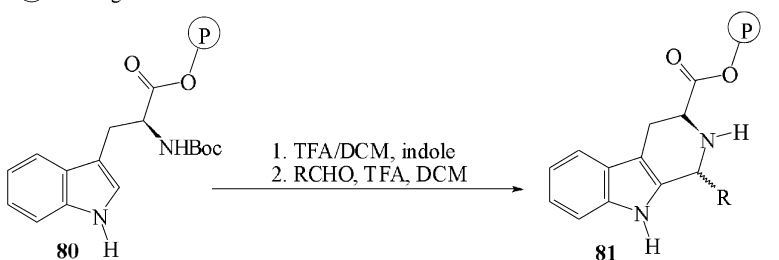

(P) $=$ Merrifield-resin

$\mathrm{R}=$ Alkyl, $\mathrm{Ph}$

Scheme 18.

\subsection{Indole 3-position modifications}

There are a number of methods for introducing substituents at C-3, since this is the preferred site for electrophilic substitution. Most of the direct functionalisations on solidphase chemistry have focused on that position. The first published functionalisation utilised the Mannich reaction as presented by Zhang et al. ${ }^{32}$ Resin-bound (Rink amide resin) 5 and 6-carboxyindoles 86 were subjected to a Mannich reaction with formaldehyde and a secondary amine in the presence of acetic acid. The obtained gramines 87 were further modified by nucleophilic substitutions with $\mathrm{KCN}$ and 2-nitroacetate $(\mathbf{8 6} \longrightarrow \mathbf{8 8 , 8 9})$. Different reaction conditions for the solid-phase Mannich reaction have been reported by Gmeiner. ${ }^{27}$ Dimethylmethyleneimmonium chloride (Böhme's salt) was used in order to avoid acidic aqueous conditions $(\mathbf{9 0} \longrightarrow \mathbf{9 1})$ (Scheme 20).
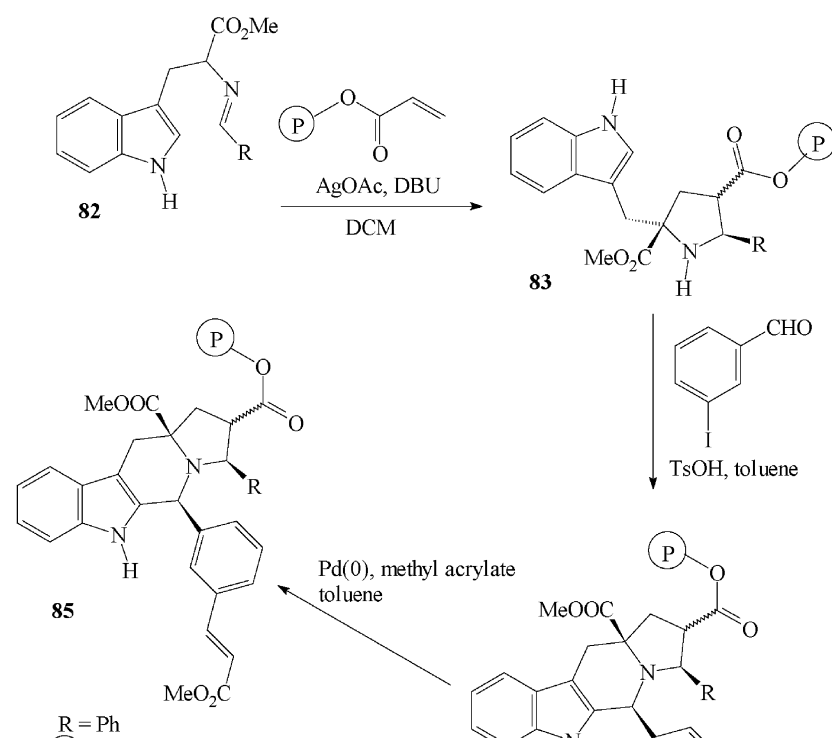

P $=$ Wang-acrylate-resin

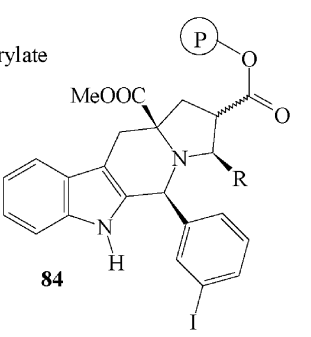

Scheme 19. 


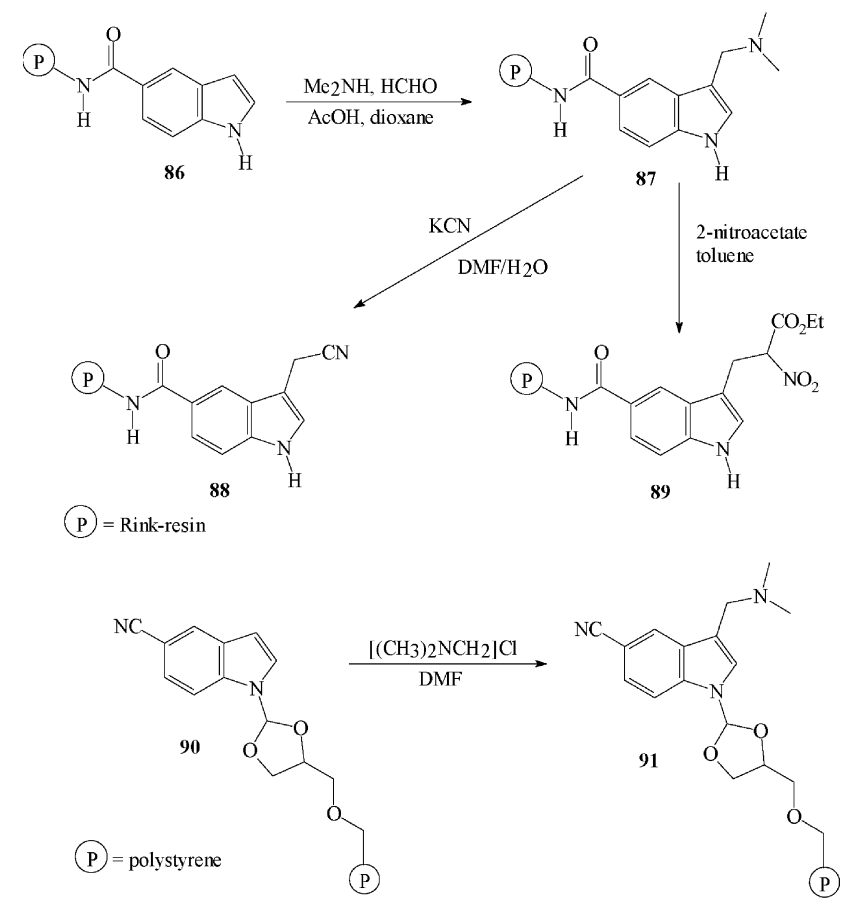

Scheme 20.

Tois and Franzén modified resin-bound 2-carboxyindoles 92 by bromination. ${ }^{41}$ Selective brominations were performed with pyridinium bromide perbromide. The brominated indoles 93 were thereafter subjected to Suzuki coupling reactions (Scheme 21). A selective iodination was also performed analogous to the solution-phase method described by Barluenga et al. ${ }^{42}$ However, the use of the iodinated indole did not increase the coupling yields. ${ }^{30}$

A synthetically-versatile resin-bound 3-indolylmercury species 96 was recently reported by Zhang et al. ${ }^{15}$ The solid-supported indole was treated with mercury(II) acetate, catalytic amount of $\mathrm{HClO}_{4}$ and $\mathrm{NaCl}$ in $\mathrm{AcOH} /$ dioxane followed by palladium-mediated coupling with methyl acrylate $(\mathbf{9 5} \longrightarrow \mathbf{9 7})$ (Scheme 22).

Solid-phase acylation of indoles at C-3 by Friedel-Crafts reaction has been demonstrated by Schultz et al. ${ }^{16}$ in their synthesis of 2,3,5-trisubstituted indoles. Aromatic acid chlorides were found to be most reactive in this $\mathrm{AlCl}_{3}$ catalysed reaction $(\mathbf{9 8} \rightarrow \mathbf{9 9})$ (Scheme 23$)$.

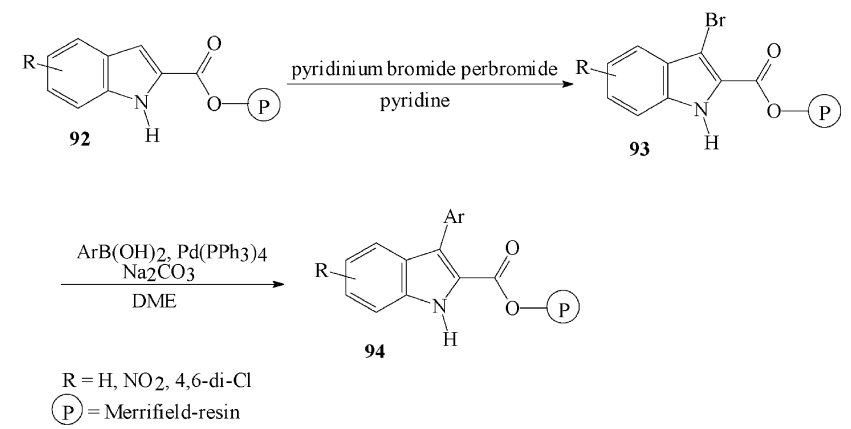

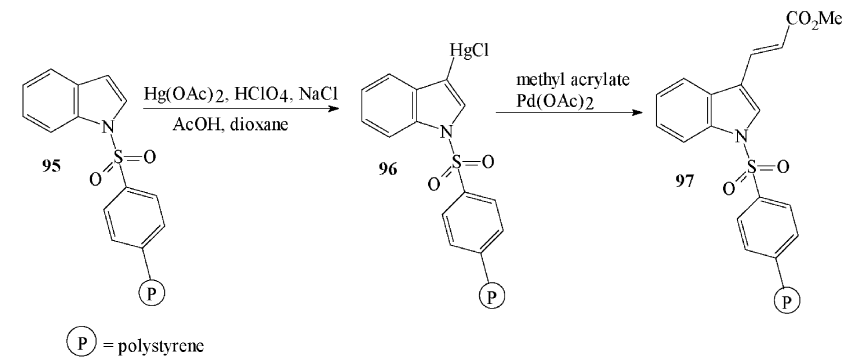

Scheme 22.

Vilsmeier formylation was adopted to solid phase by Tois and Franzén. ${ }^{43}$ The versatile aldehyde functionality at C-3 was utilised in the preparation of $O$-benzylhydroxyureas $(\mathbf{1 0 0} \longrightarrow \mathbf{1 0 4})$ (Scheme 24).

Some preliminary results for introducing a 3-cyano group to resin-bound 2-carboxyindole with a method published by Vorbrüggen ${ }^{44}$ were also very promising. ${ }^{30}$

\subsection{Functionalisations to other positions}

The only published method for the direct functionalisation of the benzenoid ring in solid phase has been reported by Herget et al. ${ }^{31}$ In their solid-phase synthesis of teleocidin analogues, a functionality at C-7 was needed. A regioselective iodination was performed with iodine in pyridine/ dioxane at $0^{\circ} \mathrm{C}$. The resulting iodides were subjected to Sonogashira coupling with acetylenes on the polymeric support $(\mathbf{1 0 5} \longrightarrow \mathbf{1 0 7})$ (Scheme 25).

Tois and Koskinen ${ }^{45}$ have recently submitted a manuscript considering the solid-phase lithiation of a 5-carboxyindole $(\mathbf{1 0 8} \rightarrow \mathbf{1 0 9 , 1 1 0})$ (Scheme 26). The precursor was tethered to an aminomethylated resin via an amide bond and subjected to lithiation. The lithiated species was quenched with an electrophilic component and the products were cleaved from the resin as phthalides described by Garibay et al. ${ }^{46}$

\section{Conclusions}

Indoles and their derivatives are perhaps amongst the most recognisable heterocyclic motifs in a myriad of natural products, pharmaceutical agents and polymers. Over 40 named reactions leading to the indole ring system have been reported, but only a few of these have been transferred to
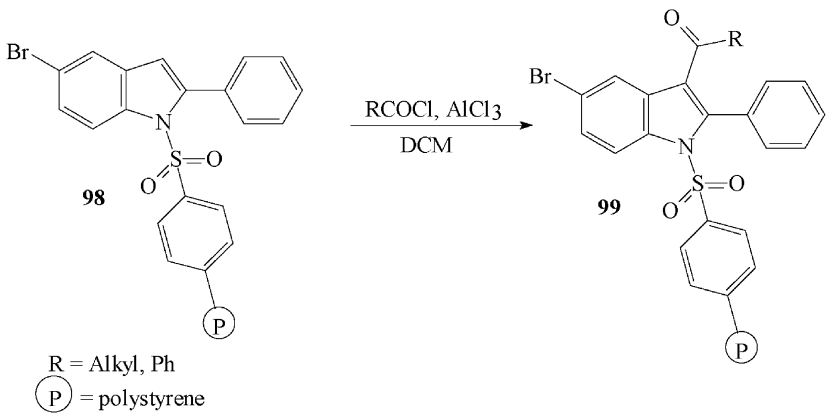

Scheme 23. 


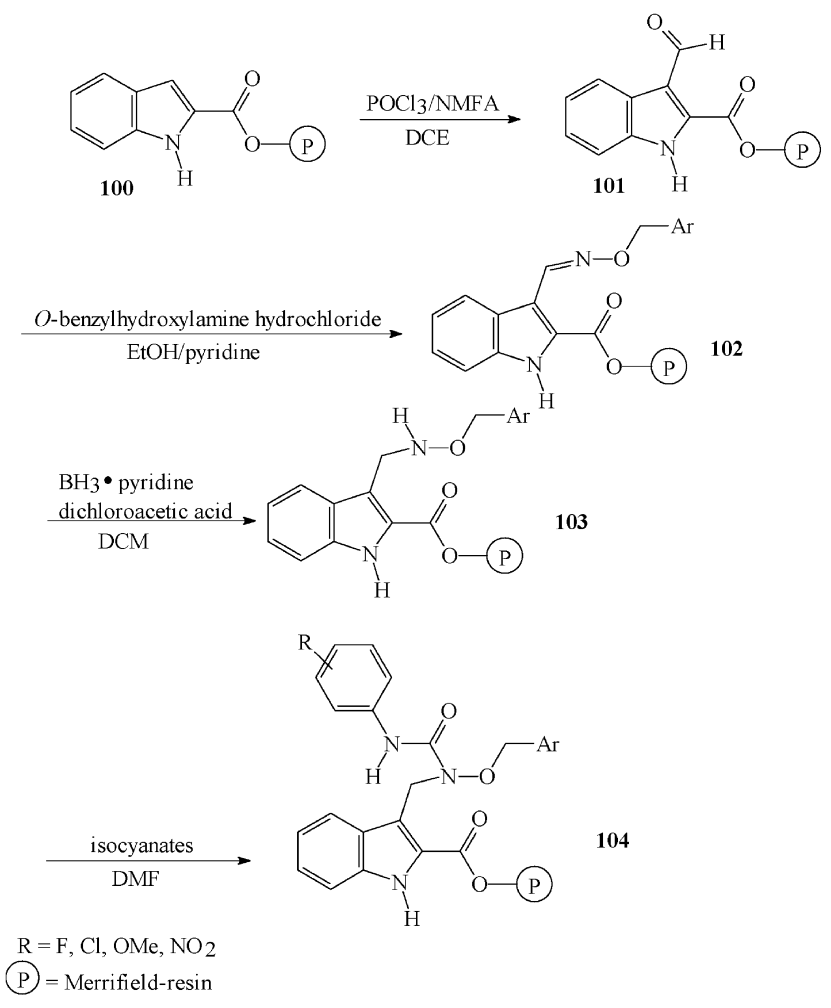

Scheme 24.

solid phase. A wide variety of new supports with better solvent compatibility and thermal stability are being developed and will allow the transformation of classical indole syntheses to solid support. It may be that a clever Julia reaction or Leimgruber-Batcho reaction will be the next method to be investigated? On the other hand, is it worth while to transfer reactions to solid phase? This question is not a trivial one. Our opinion is that when we are pondering this question we have to recall the advantages of
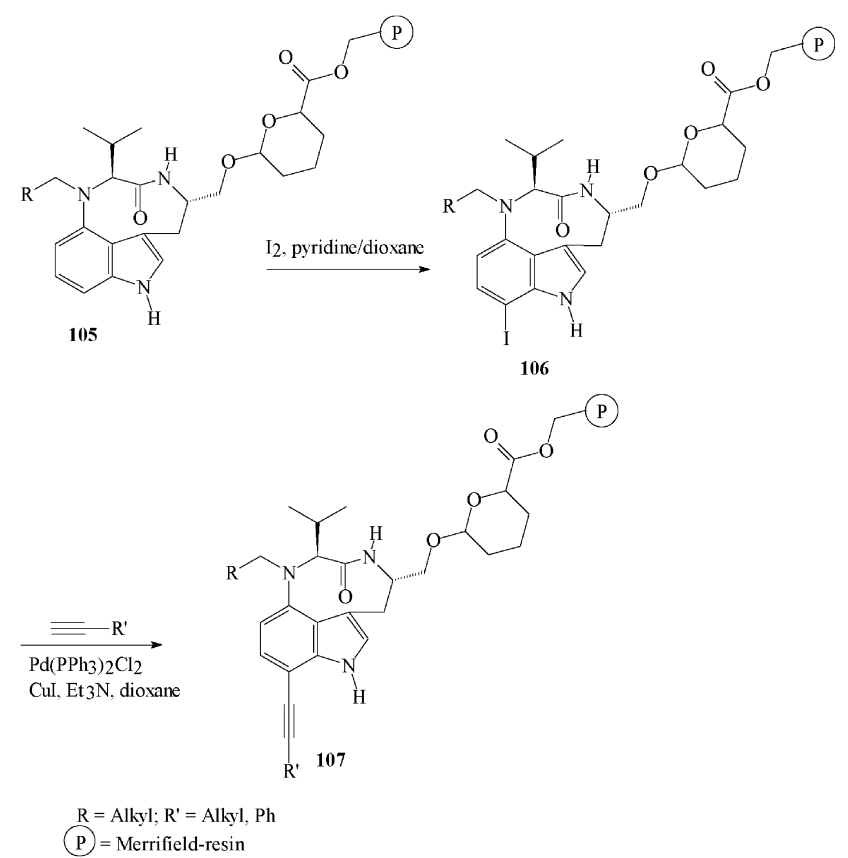

Scheme 25 .
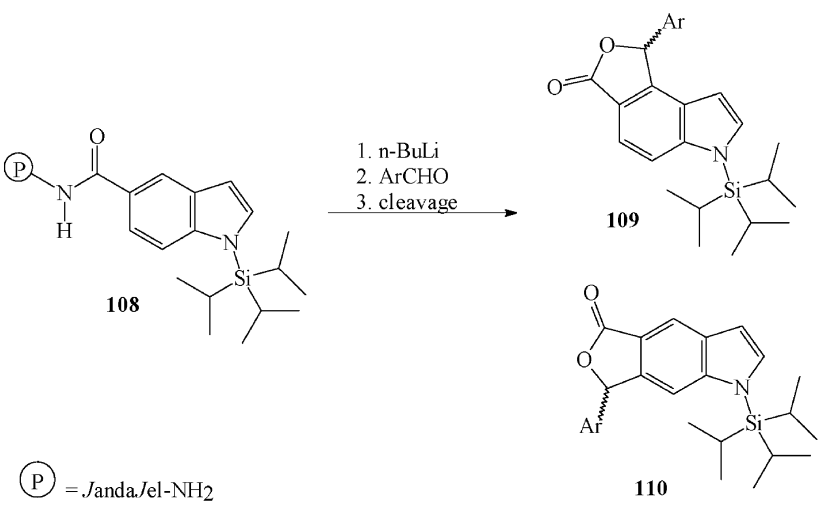

Scheme 26

solid-phase chemistry. Some important aspects are listed below.

1. Operational simplicity; simple unit operations after each reaction step, namely filtration and resin washing. Extremely important in reactions where sluggish byproducts are formed.

2. Possibility to drive the reactions to completion either with excess of reagents or reaction repetition. This could lead to better yields and higher purity.

3. Stability of resin bound molecules; sometimes the immolibilised molecules could be more stable than the corresponding molecules in solution. If the molecules need to be protected in solution the solid-phase technique can be an alternative.

4. Fast technique to optimize either the diversity of molecular structure or reaction conditions.

5. Traceless techniques; only pure compounds are cleaved from resin.

6. Automatisation if needed.

If we are just using solid-phase chemistry without thought and justification there is a possibility that solid-phase organic chemistry (SPOS) could turn out to be stupid-phase organic chemsitry. If any reaction can be done more easily in solution there is no need to transfer the reaction to solidphase. However, if some of the aforementioned benefits can be achieved it is worthwhile to consider the solid supported alternative. When we are planning a synthesis the polymer bound reagents and scavengers should also be taken into account.

Should more efforts be focused on optimizing ring synthesis of indoles rather than just directly introduce functionalities of the solid supported indole core? We already know for example several methods for direct functionalization at C-3, coupling reactions are well reported and halogenated indoles are commercially available. We also know that lithiation is possible by choosing a directing traceless linker. Most of the reported methods are still focusing on modifications of the 2, 3 or 5-positions. To obtain more diverse indole derivatives we have to explore the methods for 4, 6 and 7-position modifications in the future. Perhaps the best results can be achieved by combining the ring synthesis and direct functionalization. The indole core 
always gives new challenges for both solution phase and solid-phase organic synthesis.

\section{References}

1. Sundberg, R. J. Indoles. Academic: London, 1996.

2. Fischer, E.; Jourdan, F. Chem. Ber. 1883, 16, 6.

3. Estep, K. G.; Neipp, C. E.; Stramiello, L. M.; Adam, M. D.; Allen, M. P.; Robinson, S.; Roskamp, E. J. J. Org. Chem. 1998, 63, 5300-5301.

4. Todd, M. H.; Oliver, S. F.; Abell, C. Org. Lett. 1999, 1, 1149-1151.

5. Hutchins, S. M.; Chapman, K. T. Tetrahedron Lett. 1996, 37, 4869-4872.

6. Kim, R. M.; Manna, M.; Hutchins, S. M.; Griffin, P. R.; Yates, N. A.; Bernick, A. M.; Chapman, K. T. Proc. Natl Acad. Sci. USA 1996, 93, 10012

7. Cheng, Y.; Chapman, K. T. Tetrahedron Lett. 1997, 38, 1497-1500.

8. Yun, W.; Mohan, R. Tetrahedron Lett. 1996, 37, 7189-7192.

9. Arumugam, V.; Routledge, A.; Abell, C.; Balasubramanian, S. Tetrahedron Lett. 1997, 38, 6473-6476.

10. Zhang, H.-C.; Maryanoff, B. E. J. Org. Chem. 1997, 62, 1804-1809.

11. Fagnola, M. C.; Candiani, I.; Visentin, G.; Cabri, W.; Zarini, F.; Mongelli, N.; Bedeschi, A. Tetrahedron Lett. 1997, 38, 2307-2310.

12. Zhang, H.-C.; Brumfield, K. K.; Maryanoff, B. E. Tetrahedron Lett. 1997, 38, 2439-2442.

13. Smith, A. L.; Stevenson, G. I.; Swain, C. J.; Castro, J. L. Tetrahedron Lett. 1998, 39, 8317-8320.

14. Collini, M. D.; Ellingboe, J. W. Tetrahedron Lett. 1997, 38, 7963-7966.

15. Zhang, H.-C.; Ye, H.; Moretto, A. F.; Brumfield, K. K.; Maryanoff, B. E. Org. Lett. 2000, 2, 89-92.

16. Wu, T. Y. H.; Ding, S.; Gray, N. S.; Schultz, P. G. Org. Lett. 2001, 3, 3827-3830.

17. Yamazaki, K.; Kondo, Y. J. Comb. Chem. 2002, 4, 191-192.

18. Wagaw, S.; Yang, B. H.; Buchwald, S. L. J. Am. Chem. Soc. 1998, 120, 6621-6622.

19. Wagaw, S.; Yang, B. H.; Buchwald, S. L. J. Am. Chem. Soc. 1999, 121, 10251-10263.

20. Wacker, D. A.; Kasireddy, P. Tetrahedron Lett. 2002, 43, 5189-5191.

21. Hughes, I. Tetrahedron Lett. 1996, 37, 7595-7598.

22. Ketcha, D. M.; Wilson, L. J.; Portlock, D. E. Tetrahedron Lett. 2000, 41, 6253-6257.
23. Stephensen, H.; Zaragoza, F. Tetrahedron Lett. 1999, 40, 5799-5802.

24. Nicolaou, K. C.; Roecker, A. J.; Pfefferkorn, J. A.; Cao, G.-Q. J. Am. Chem. Soc. 2000, 122, 2966-2967.

25. Macleod, C.; Hartley, R. C.; Hamprecht, D. W. Org. Lett. 2002, 4, 75-78.

26. Smith, A. L.; Stevenson, G. I.; Lewis, S.; Patel, S.; Castro, J. L. Bioorg. Med. Chem. Lett. 2000, 10, 2693-2696.

27. Kraxner, J.; Arlt, M.; Gmeiner, P. Synlett 2000, 125-127.

28. Hübner, H.; Kraxner, J.; Gmeiner, P. J. Med. Chem. 2000, 43, $4563-4569$.

29. Tois, J.; Franzén, R.; Aitio, O.; Huikko, K.; Taskinen, J. Tetrahedron Lett. 2000, 41, 2443-2446.

30. Tois, J.; Franzén, R. Unpublished results.

31. Meseguer, B.; Alonso-Díaz, D.; Griebenow, N.; Herget, T.; Waldmann, H. Chem. Eur. J. 2000, 6, 3943-3957.

32. Zhang, H.-C.; Brumfield, K. K.; Jaroskova, L.; Maryanoff, B. E. Tetrahedron Lett. 1998, 39, 4449-4452.

33. Mann, G.; Hartwig, J. F.; Driver, M.; Fernández-Rivas, C. J. Am. Chem. Soc. 1998, 120, 827-828.

34. Old, D. W.; Harris, M. C.; Buchwald, S. L. Org. Lett. 2000, 2 , 1403-1406.

35. Mederski, W. W.; Lefort, M.; Germann, M.; Kux, D. Tetrahedron 1999, 55, 12757-12770.

36. Mayer, J. P.; Bankaitis-Davis, D.; Zhang, J.; Beaton, G.; Bjegarde, K.; Andersen, C. M.; Goodman, B. A.; Herrera, C. J. Tetrahedron Lett. 1996, 37, 5633-5636.

37. Kaljuste, K.; Undén, A. Tetrahedron Lett. 1995, 36, 9211-9214.

38. Yang, L.; Guo, L. Tetrahedron Lett. 1996, 37, 5041-5044.

39. Mohan, R.; Chou, Y.-L.; Morrissey, M. M. Tetrahedron Lett. 1996, 37, 3963-3966.

40. Dondas, H. A.; Grigg, R.; MacLahlan, W. S.; MacPherson, D. T.; Markandu, J.; Sridharan, V.; Suganthan, S. Tetrahedron Lett. 2000, 41, 967-970.

41. Tois, J.; Franzén, R.; Aitio, O.; Laakso, I.; Huuskonen, J.; Taskinen, J. Comb. Chem. High Throughput Screening 2001, 4, 521-524.

42. Barluenga, J.; González, J. M.; García-Martin, M. A.; Campos, P. J.; Asensio, G. J. Org. Chem. 1993, 58, 2058-2060.

43. Tois, J.; Franzén, R.; Aitio, O.; Laakso, I.; Kylänlahti, I. J. Comb. Chem. 2001, 3, 542-545.

44. Vorbrüggen, H.; Krolikiewicz, K. Tetrahedron 1994, 50, 6549-6558.

45. Tois, J.; Koskinen, A. Tetrahedron Lett. 2003, 44, 2093-2095.

46. Garibay, P.; Vedsø, P.; Begtrup, M.; Hoeg-Jensen, T. J. Comb. Chem. 2001, 3, 332-340. 


\section{Biographical sketch}

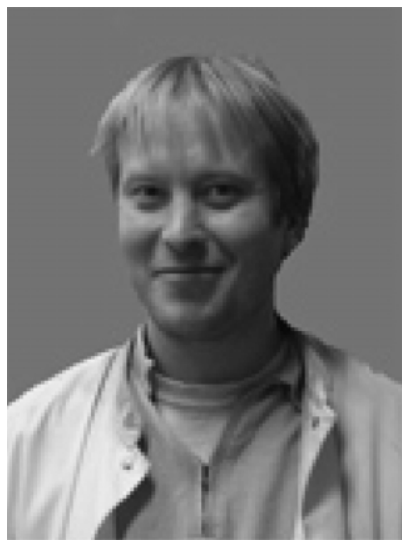

Jan Tois was born in Espoo, Finland. He graduated from University of Helsinki in 1997. In 1998 he started his PhD studies under the supervision of Professor Robert Franzén in University of Helsinki. In 2001 he continued his PhD studies under the supervision of Professor Ari Koskinen in Helsinki University of Technology. His research is focused on solid-phase techniques, indole chemistry and catalyst development.

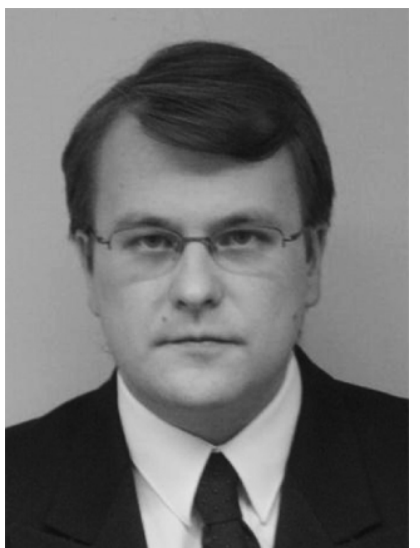

Robert G. Franzén (1966) received his PhD in organic Chemistry from Åbo Akademi University, Finland in 1995, and then continued his work as a postdoctoral fellow in the field of bio-organic chemistry at NIES ( $\mathrm{Dr}$ Masatoshi Morita) in Tsukuba, Japan until 1997. Next 3 years he worked in the field of drug discovery at Helsinki University, and returned back to Japan (Tokyo University) to work as a JSPS fellow in the group of Professor Masakatsu Shibasaki until 2002, when he was appointed as Professor of Chemistry at Tampere University of Technology. He is recipient of the ACS/CAS Science Spotlight reward (2002) and his current research interests include catalytic asymmetric synthesis, combinatorial chemistry, solid phase chemistry and heterocyclic chemistry.

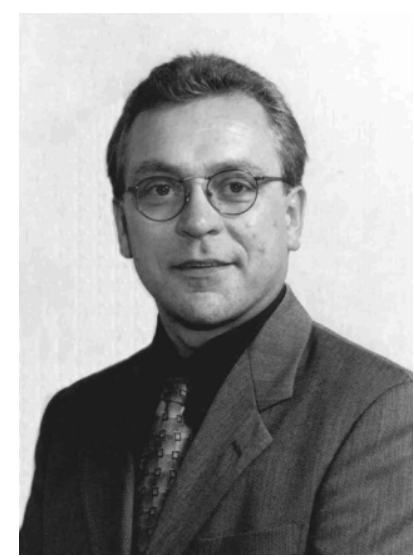

Ari M. P. Koskinen was born on 22 September, 1956 in Finland. He received his MSc (Chem. Engng) in 1979 (with Professor T. Hase), Licentiate in Technology in 1982 and Doctor of Technology in 1983 (with Professor M. Lounasmaa), all at the Helsinki University of Technology, Finland. After postdoctoral studies at the University of California, Berkeley (Professor Henry Rapoport 1983-85 and 1987-88), as well as an appointment as a Project Leader in New Drug Development at Orion Corporation-Fermion, Finland (1985-1987), he joined the University of Surrey, England, as a lecturer in 1989. He was appointed as Professor of Chemistry (especially Synthetic Organic Chemistry) at the University of Oulu, Finland in 1992, and transferred to his current position at the Helsinki University of Technology in August, 1999 as Professor of Organic Chemistry (the old Gustav Komppa chair). He also holds docentships at the Universities of Helsinki and Turku, Finland. Professor Koskinen is a member of the Finnish Academy of Sciences and Letters since 2003.

The main objective of his research interest is to develop novel synthetic methods capable of being transferred into (industrially) applicable synthetic technologies and construction of complex natural and non-natural compounds with multiple chiral centers in enantiopure form.

$\mathrm{He}$ is the author or co-author of some 100 publications, 10 patents and two books. Professor Koskinen is active both nationally and internationally (member of the Scientific Advisory Board of the Finnish Chemical Industry Federation, a founding member of the European Chemical Society, European Society for Combinatorial Sciences, and management committees of EU-research programs). 